\title{
“HOMOSSEXUALISMO: SEXUALIDADE E VALOR", DE SAMUEL RAWET - UM TEXTO FUNDADOR DA TEORIA QUEER BRASILEIRA ${ }^{1}$
}

\section{“HOMOSSEXUALISMO: SEXUALIADE E VALOR", BY SAMUEL RAWET - A TEXT FOUNDER OF BRAZILIAN QUEER THEORY}

\author{
David William Foster*
}

\begin{abstract}
Resumo
O ensaio de Samuel Rawet "Homossexualismo: sexualidade e valor" (1970) é o primeiro tratado detalhado na cultura brasileira do fenômeno da chamada homossexualidade. Rawet, num verdadeiro gesto de inovação ideológica, se distancia dos modelos que vêm a homossexualidade como, alternativamente, um pecado, uma patologia e um ato criminoso, para defendê-lo como exemplo de livre escolha humana que ele fundamenta nos valores existenciais da condição humana.
\end{abstract}

Palavras-chave: Samuel Rawet, Sexualidade Humana, Homossexualidade, Existentcialismo.

\begin{abstract}
Samuel Rawet's essay "Homossexualismo: sexualidade e valor" (1970) is the first detailed examination in Brazilian culture of the phenomenon of so-called homosexuality. Rawet, in a true gesture of ideological innovation, distances himself from models that see homosexuality as, alternatively, a sin, a pathology, and a criminal act and defends it as an example of free human choice that he grounds philosophically in existential values of the human condition.
\end{abstract}

Keywords: Samuel Rawet; Human Sexuality, Homosexuality, Existentialism.

\footnotetext{
${ }^{1}$ Traduzido do inglês por Lizandro Carlos Calegari.

* Professor na Arizona State University.
} 
[A] consideração de homem como estrutura aberta, sem começo nem fim, uma definição do ato de pensar como ato de deslocar, daqui para aqui mesmo, e da transcendência compreendida como um movimento do ato de pensar, movimento que conduz de um pensamento a outro, após o nada do intervalo, foi com esses elementos que dei início ao trabalho. (RAWET, 2008, p. 28)

Embora seja bastante conhecido por suas narrativas ficcionais curtas e altamente elaboradas acerca da vida judaico-diaspórica no Brasil, muitas vezes dotadas de uma envergadura profética ou apocalíptica, Samuel Rawet (1929-1984) também escreveu importantes textos sobre filosofia religiosa. No entanto, seu longo ensaio Homossexualismo: sexualidade e valor (1970) ganhou destaque tanto pelo fato de ter sido publicado como um panfleto independente quanto pela forma como o autor abordou questões queer que estavam começando a se cristalizar no pensamento sociopolítico ocidental $^{2}$. O referido ensaio surgiu, então, num momento em que, no Ocidente, tanto a direita quanto a esquerda condenavam a assim chamada homossexualidade. A direita a concebia como uma prática pecaminosa merecedora de punição; a esquerda, por sua vez, como um sinal da decadência burguesa com moral pervertida.

O ensaio de Rawet, que carrega nítidos traços de sua prosa extremamente complexa, é um importante texto fundador daquilo que, hoje, chamaríamos de uma bibliografia sobre uma teoria queer brasileira. Como tal, ele surgiu antes de outros textos similares que apareceram em outras sociedades latino-americanas e se filia a Bom-Crioulo (1895), de Adolfo Caminha, o primeiro romance gay da América Latina, na tentativa de sistematizar uma significante reflexão brasileira no que concerne à virada queer, que começava a se delinear a partir de então. Apesar de o ensaio de Rawet ter sido frequentemente ignorado por estudiosos da cultura queer brasileira (tais como Lopes ${ }^{3}$, MacRae, Trevisan, Parker e Green), ele requer atenção não apenas por articular fortes posições sobre questões queer, mas também por ser um texto genuinamente pessoal, escrito por um judeu bastante comprometido com questões de marginalização e de exílio e marcado por uma vida abertamente queer.

Homossexualismo: sexualidade e valor - embora não mencione diretamente JeanPaul Sartre, mas faça alusão à palavra "existencialista" uma única vez ao longo de suas

\footnotetext{
${ }^{2}$ Deve-se ter em mente que o primeiro volume de $A$ história da sexualidade, de Michel Foucault, apareceu em 1976.

${ }^{3}$ Lopes (2002, p. 134) menciona uma das narrativas de Rawet, alegando que o autor merece mais estudos, mas não menciona o ensaio de 1970 sobre a homossexualidade.
} 
vinte páginas ${ }^{4}$ - está bastante afinado com o que poderíamos chamar de uma apreciação claramente crucial sobre o assunto. Uma das premissas ideológicas básicas do texto de Rawet diz respeito ao princípio insistentemente reiterado (em letras maiúsculas) de que “O HOMEM ESCOLHE A FORMA DA SUA SEXUALIDADE” (RAWET, 2008, p. 28, $36)^{5}$ e de que "a ambiguidade ainda flutua na consideração de que ser como natureza sob a forma de homem é ser eticamente, e ser homem sob forma de natureza é ser valor" (p. $29)^{6}$. Assim, o posicionamento de Rawet resume-se categoricamente à tese de que a vida sexual dos indivíduos é parte do vasto empreendimento do "querer tornar-se algo", e isso, a rigor, pertence a seu legado como sujeitos humanos num universo hostil, em que eles, e somente eles, podem decidir como sobreviver eticamente. Nesse ponto, o autor deixa claro que está se referindo a "O Homem, com H maiúsculo, sempre” (p. 21), de forma que “Homem”, aqui, é qualquer coisa, exceto uma designação sexista excludente.

Sendo assim, Rawet posiciona-se radicalmente em oposição aos conceitos predominantes de homossexualidade que emergiram há cinquenta anos (esta é a razão pela qual empregarei estrategicamente uma palavra que, normalmente, não faz parte de meu vocabulário teórico). Enquanto o autor concebe a sexualidade do indivíduo como consequência de decisões pessoais absolutamente audaciosas, conforme rege o existencialismo, devemos reconhecer que este, normalmente, não é formulado com base na liberdade de escolha da sexualidade; visto que talvez se acredite que as formulações anárquicas antecedentes aos princípios do amor livre possam continuar prevalecendo de forma adequada. Essa ideia de amor livre, convém ressaltar, alimenta a proposição modernista da homossexualidade como uma marca de privilégio e favor (Cocteau e companhia, por exemplo).

A propósito, as setecentas páginas do livro Saint Genet (1952), de Sartre, inevitavelmente, tocam no que se deve considerar tanto para o que se define como a anarquia sexual de grau zero de Genet quanto para se entender o seu compromisso com a liberação desenfreada da energia sexual como parte da autoconstrução existencial do indivíduo (ambos os princípios estão ancorados em dois ícones sexuais de Genet: os personagens Everyman e Querelle). Apesar disso, não é possível encontrar qualquer

\footnotetext{
4 “Existencial (ai, a palavra!)” (RAWET, 2008, p. 34).

${ }^{5} \mathrm{O}$ itálico é de Rawet.

${ }^{6}$ Os vocábulos em itálico constam no texto de Rawet.
} 
reflexão mais prolongada por parte do autor no que tange à importância exemplar de Genet para a definição da sexualidade, em geral, ou da homossexualidade, em particular ${ }^{7}$.

Certamente, seria justo dizer que o discurso emergente sobre a defesa da homossexualidade - a defesa de sua existência, a defesa da dignidade daqueles a quem é atribuída, a defesa da legitimidade para agir sobre o desejo homossexual - não é amparado pelo amplo direito dos indivíduos de obedecerem às suas pulsões sexuais. $\mathrm{Na}$ época em que Rawet escreveu o seu ensaio - lembre-se de que foi publicado como um panfleto em 1970 -, a homossexualidade ainda era uma espécie de amor que não ousava mencionar o seu nome (isto é, não podia falar por si em seu próprio direito), sendo, então, um não amor declarado, que o Estado continuava a patologizar e a criminalizar, juntamente com vários outros projetos que levavam à sua erradicação. Isso era um fato tanto no Brasil de Rawet quanto nos Estados Unidos de Gore Vidal, James Baldwin e John Rechy (apenas para mencionar três autores americanos que escreveram romances de temática abertamente homossexual em 1948, 1956 e 1963, respectivamente $)^{8}$.

As ideias essencialistas sobre o desejo homoerótico sempre gravitaram em torno da presunção de ele ser um problema psicológico (isto é, prefere-se a afrontosa proposição de que a homossexualidade é um "erro" da natureza ou mesmo do próprio Deus), uma marca de Caim (a embriaguez do naturalismo e de outros genes maus) ou um desafio perversamente decretado pela vontade de Deus (mas qual mandamento ele transgride?). $\mathrm{Na}$ verdade, é claro, a ideia de sexo transgressor (isto é, qualquer prática sexual que não atenda à heteronormatividade patriarcal compulsória), como uma provocação, adéqua-se ao critério existencialista de absoluto livre-arbítrio, mas se caracteriza (lembre-se de que ele não está falando em seu próprio nome) sempre como um empreendimento destrutivo, e nunca construtivo ou glamoroso.

\footnotetext{
${ }^{7}$ No que concerne aos homossexuais como uma importante categoria do outro, para Sartre, confira CHARMÉ (1991, p. 258-260).

Sartre faz certas confusões para tentar explicar a homossexualidade de Genet, sugerindo que se trata de uma escolha que ele deliberadamente fez para afirmar sua marginalização social como consequência de seus precoces desentendimentos com a lei (SARTRE, 1963, p. 90-91). Nesse ponto, o autor vai além a fim de contradizer a própria afirmação de Genet, segundo quem seus sentimentos sexuais, aos dez anos de idade, antecipavam sua careira de ladrão. Embora esse não seja um entendimento adequado de como a homossexualidade poderia ser uma escolha livremente determinada, ele faz, do seu jeito, um paralelo com as ideias de Rawet acerca da homossexualidade como uma escolha existencial. Se Rawet tivesse lido o longo ensaio de Sartre sobre Genet, que foi originalmente publicado em 1952, ele não mencionaria isso.

${ }^{8}$ Algumas dessas obras são: A cidade e o pilar (1948), de Vidal, O quarto de Giovanni (1958), de Baldwin, e As cidades da noite (1963), de Rechy. É importante ter em mente que, desses três romances fundadores da literatura gay norte-americana, dois deles foram escritos por homens de cor (Baldwin era afro-americano, e Rechy é americano de origem mexicana).
} 
O discurso emergente do sujeito revolucionário (não sem uma profunda tradição homofóbica, como na defesa estridente e mesmo violenta dos valores heteronormativos feita por Che Guevara) ainda tinha que introjetar a liberação sexual no cerne de sua ideologia (como os "Montoneros", na Argentina, na década de 1960, estavam acostumados a entoar: "No somos ni putos ni faloperos / somos montoneros" [faloperos = consumidores de drogas]), e, quando o que podemos chamar sinteticamente de prática hippy do amor livre realmente veio à tona, estava-se ainda muito distante de se abraçar, de fato, a homoafetividade e o desejo homoerótico.

Tanto nos Estados Unidos quanto no Brasil, a luta pelo reconhecimento dos direitos gays é, como nós todos sabemos, longa (e arriscada, especialmente quando se leva em conta o que aconteceu quando o grupo LBGTQ tornou-se homonormativo). Há diferenças estruturais significativas entre essas duas sociedades. Embora ambas considerem a homossexualidade como uma perversão psicológica, no Brasil, condena-se apenas a sua exibição pública, sob a alegação da existência de normas de decência que regem o comportamento humano, ao passo que, nos Estados Unidos, desaprova-se tanto essa exibição pública quanto os chamados atos consentidos de comportamentos privados desviantes. Assim, forja-se rotineiramente uma cadeia semântica de suposições, subentendendo-se, invitavelmente, a existência de atos privados desviantes, sem qualquer prova ou sem ninguém para oferecer um contradiscurso eficiente ou convincente.

Um componente central da luta pelos direitos gays tem sido o compromisso quase universal (principalmente se for estratégico ou firmemente mantido como uma convicção) de assegurar que ser gay consiste na projeção daquilo que o indivíduo é e, por isso, não pode ser moralmente condenado. As estatísticas sobre questões referentes a padrões de biodiversidade têm mostrado inúmeras vezes que, quando se alude aos homossexuais, estes são equiparados a pessoas com deficiência, para quem a sociedade se mantém inerte, a exemplo do que acontece com os cegos ou coxos. A chamada teoria crip funciona a partir dessas bases ${ }^{9}$ e parece ter desempenhado um discurso muito eficiente politicamente. A ideia de que a suposta homossexualidade seja inerente aos sujeitos tem sido responsável pelo aumento de sua aceitação (como acontece em algumas regiões da América Latina, como um componente integral da ideologia da Nova Esquerda) e, inquestionavelmente, é

\footnotetext{
${ }^{9}$ Cf. McRUER, 2006.
} 
um sólido pilar para a defesa da legitimidade do casamento gay nos Estados Unidos ${ }^{10}$. Não há diferença entre ser gay e ser cego. Acomode-se e siga em frente ("E durma-se!”, diz Rawet [2008, p. 31]).

Porém, todo esse discurso sobre direitos humanos e toda essa atenção dada às pessoas com necessidades especiais podem não ter importância alguma para Rawet (assim como a sociedade estadunidense pós-Segunda Guerra Mundial não tinha nada a ver com as forças políticas brasileiras daquela época). Não sei ele teria aderido aos direitos humanos ou aos direitos das pessoas portadoras de deficiência na formulação de sua teoria sobre a homossexualidade, mas elas teriam constituído uma instância inviolável da base existencialista de seu pensamento. É irrelevante que os exemplos reais fornecidos por Rawet sobre homossexualidade sejam um tanto inconsistentes e incompletos para os padrões de conhecimento de hoje no que diz respeito ao potencial sexual queer do corpo humano. O autor permaneceu firmemente ligado ao que ficou conhecido como princípios inversionistas da sexualidade desviante: o homem que deseja assumir o papel da mulher, a mulher que deseja assumir o papel do homem, tudo calcado na confusa dicotomia ativo/ passivo, que tem pouco a ver com o verdadeiro comportamento sexual dos seres humanos.

Até 1977, Charles Silverstein e Edmund White não haviam publicado The joy of gay sex $[\text { A alegria do sexo gay }]^{11}$, e Rawet, na formulação de seu pensamento, leva em conta aquilo que fazia parte do discurso público daquela época sobre a homossexualidade: a inversão do desejo sexual em sujeitos sociais que estavam, todavia, ainda firmemente presos ao binarismo sexista formulado a partir do sexo biológico, das categorias sociais de feminino e masculino de ser no mundo, da configuração psicológica e do amadorismo sexual derivado desse binarismo biológico. Como consequência, para Rawet, por exemplo, seria necessário estímulo anal para que o homem gay atingisse seu orgasmo, em virtude de ter havido um deslocamento da vagina feminina para o ânus masculino. Contudo, ao mesmo tempo em que ele se opõe a tais esquematismos, ele não consegue ir além e resumir a essência do comportamento sexual humano num sentido pronunciadamente mecanicista:

\footnotetext{
${ }^{10}$ Algo parecido aconteceu na Argentina. O país fez com que os demais países da América pensassem de forma diferente a questão em 2010.

${ }^{11}$ Confira as traduções portuguesas dos americanos Alicia Gallotti e Rafael Ruiz (2005). Joy of Gay Sex foi o primeiro manual de consumo massivo a promover a naturalidade dos chamados atos homossexuais. Limitavase ao conhecimento informal e popular sobre atos homossexuais, conhecimento que primava, falsamente, o sexo anal.
} 
E para sermos breves resumiremos sexualidade em:

Exitação

penetração ativa ou passiva

ejaculação ou orgasmo, ou ambos

presença de três consciências, eu-tu-ele. $(2008$, p. 36)

O que não é irrelevante, entretanto, é a convicção de Rawet de que a sexualidade é um componente relacionado ao exercício da absoluta liberdade existencial humana, por meio do qual, então, seja qual for a sexualidade que se queira contemplar (hoje, teríamos um quadro de consentimento, sem qualquer tipo de exploração, é claro), é válido o empreendimento e a iniciativa de cada um para a construção do seu lugar no universo. Essa formulação tem algumas implicações. Uma delas diz respeito à rejeição das crenças sexológicas hegemônicas, sejam elas de cunho médico ou, mais especificamente, psiquiátrico, segundo as quais os indivíduos se constituem numa estrutura fechada. De um ponto de vista freudiano, esse sistema pode ser analisado e reconstruído em direção a uma vida mental supostamente mais saudável (mesmo quando Freud finalmente defende a homossexualidade e argumenta que se trata de algo com o qual se pode viver de maneira feliz). A questão, aqui, inquestionavelmente, é a de que não se pode ser condenado por aquilo que se é: "Em todos os ensaios, todos, que encontrei sobre a sexualidade, um ponto sempre me pareceu falho: o caráter definido, totalizado, imutável, o caráter absoluto de homem como ser, mais imutável do que a eternidade” (p. 30). Ele rejeita qualquer generalização que chegue ao "ponto de transformar o indivíduo em sistema fechado, portador de potencialidades definitivas" (p. 31) e é enfático: “Odeio a sistematização" (p. 36).

Como um narrador de romance, Rawet fala de sua própria experiência no submundo sexual do Rio de Janeiro (uma caracterização que ressalta a questão da decência pública mencionada acima), e um dos componentes narrativos mais fascinantes do seu ensaio é o homem que peregrina, indo de um bar a outro, recolhendo dados e fazendo jornalismo amarelo, sendo um de seus pilares a transgressão e o escândalo sexual. A admiração de Rawet por tais publicações, e para os benefícios sociais desses perambulantes, é evidente: é o verdadeiro material da vida sexual humana. Por que se prender às rígidas classificações fornecidas por aquelas formulações científicas inúteis, que não têm quase nada a ver com as realidades baixa e suja do corpo humano, se, por alguns centavos, pode- 
se saborear, com detalhes escabrosos, apresentados talvez com minúcias mais sedutoras, a carne abarrotada de sexualidade humana vivida e, certamente, o melhor escândalo pelo dinheiro, a homossexualidade? Complementa Rawet:

Guardo o nome do vendedor de jornais: Elias Gomes. É bem mais importante do que muita besta erudita. É mais importante que qualquer filósofo. Muito mais importante que teorias confusas claramente expostas, e definitivas. Não é bom o calor da vida que ele comunica, isto é lugar-comum de subliteratura barata, esquema lógico fornecido pronto para uma estética de quinta classe para homens da mesa. O que ele comunica é uma fratura, uma abertura, com a grandeza e o humor do que dominam a ambiguidade das palavras e com a generosidade dos que não se sentem obrigados a se horrorizar com o horror, obrigação a mascarar um sentimento hipócrita e a impedir o horror do horror autêntico. Elias Gomes tem nome de profeta. (2008, p. 40-41)

Esta é uma formulação absolutamente fascinante do valor do discurso social marginal - e é importante recuperá-lo e mostrá-lo - enquanto uma estratégia do pensamento de contestação e de transgressão, a qual pode mostrar como a vida sexual dos sujeitos sociais realmente funciona e como ela pode e deve ser crucial para a construção ética da subjetividade existencial. Significativamente, em desacordo com as ideologias sexuais em vigor à sua época, as formulações de Rawet se perdem, por assim dizer, na desordem. No entanto, hoje, é necessário recuperá-las e entendê-las, a fim de se verificar o quão importantes são para a afirmação da subjetividade sexual individual queer como parte, pelo menos, da assim chamada Maré Rosa que está acontecendo na América Latina $^{12}$ e que é acompanhada pelo reconhecimento daquilo que continuamos a chamar, ainda que diferentemente, de direitos gays e direitos lésbicos. Parte do interesse retórico do ensaio de Rawet incide sobre essa súplica à experiência pessoal e à figura quase mítica do ambulante escandaloso. Tanto uma quanto a outra partem do princípio da modéstia intelectual no que concerne ao conhecimento de Rawet acerca das teorias dos sexólogos e mesmo do latim a que tinham acesso com frequência, com o intuito de não chamar seus nomes próprios no vernáculo dos sujeitos sociossexuais vivos.

Não sei se é realmente apropriado caracterizar o ensaio de Rawet como apocalíptico, conforme os termos com que Lindstrom tem debatido suas obras ficcionais (2010), embora esteja claro que ele tenha se empenhado intensamente em repudiar crenças e valores prevalecentes no que tange à ética sexual e, portanto, esteja muito engajado numa

\footnotetext{
${ }^{12}$ Como apresentado no Simpósio Maré Rosa da América Latina, realizado na Universidade de Pittsburgh, nos dias 14 e 15 de novembro de 2014.
} 
reestruturação radical daquilo que os princípios éticos poderiam significar. Em comunhão com a retórica de Homossexualismo: homossexualidade e valor, Rawet se detém nas questões centrais de imigração e exílio que predominam em sua escrita ficcional:

E os valores do cotidiano têm que ser reconquistados sempre. São valores próprios, mesmo que idênticos aos adotados. Somos todos estrangeiros em nossa casa. Todos emigrantes e imigrantes, daqui para aqui mesmo. A personagem que cada um é representa uma conquista necessária. Conquista individual e social. Cada um representa alguma coisa. Só de um ato livre nasce realmente uma relação humana ${ }^{13}$. (2008, p. 48)

Estas são, poderíamos dizer, propostas que estão totalmente alinhadas à atual Maré Rosa na América Latina, mesmo quando seus proponentes podem não ter em mente nenhuma subjetividade sociossexual. Porém, a escrita dessa subjetividade, quando realizada de maneira adequada, terá o ensaio de Rawet como uma grande âncora bibliográfica.

${ }^{13}$ As palavras em itálico são de Rawet. 


\section{Bibliografia}

CHARMÉ, S. Z. Sartre's Images of the Other and the Search for Authenticity. Human Studies, v. 14, n. 4, p. 251-264, 1991.

GALlOTTI, A. Kama sutra gay: para desfrutar o máximo da sexualidade. São Paulo: Editora Planeta do Brasil, 2005.

GREEN, J. Beyond Carnival: male homosexuality in twentieth-century Brazil. Chicago: University of Chicago Press, 1999.

LINDSTROM, N. Los usos del discurso profético en la narrativa de Samuel Rawet. Revista de Crítica Literaria Latinoamericana, EUA, Tufts University, n. 72, p. $437-$ $458,2010$.

LOPES, D. O homem que amava rapazes e outros ensaios. Rio de Janeiro: Aeroplano, 2002.

MacRAE, E. A construção da igualdade: identidade sexual e política no Brasil da "abertura". Campinas: UNICAMP, 1990.

McRUER, R. Crip Theory: cultural signs of queerness and disability. New York: New York University Press, 2006.

PARKER, R. Beneath the Equator: cultures of desire, male homosexuality, and emerging gay communities in Brazil. New York: Routledge, 1998.

RAWET, S. Homossexualismo: sexualidade e valor. In: BINES, R. K; TONUS, J. L. (Org.). Ensaios reunidos. Rio de Janeiro: Civilização Brasileira, 2008, p. 23-49.

SALEM SZKLO, G. Rawet, Samuel (Brazil; 1929-84). Jewish writers of Latin America: a dictionary. New York: Garland Publishing, 1997.

SARTRE, J. Saint Genet. New York: New American Library, 1963.

TREVISAN, J. S. Devassos no paraíso: a homossexualidade no Brasil, da colônia à atualidade. Rio de Janeiro: Record, 2002. 